Godel, ThIERRY, “La aplicación espacial de la responsabilidad penal de la empresa en el derecho penal suizo a la luz de la reciente jurisprudencia del Tribunal Federal", Nuevo Foro Penal, 94, (2020).

\title{
La aplicación espacial de la responsabilidad penal de la empresa en el derecho penal suizo a la luz de la reciente jurisprudencia del Tribunal Federal
}

The spatial application of the company's criminal liability in Swiss Criminal law in light of the recent jurisprudence of the Federal Court

THIERRY GODEL ${ }^{*}$

Fecha de recepción: 10/05/2020 Fecha de aceptación: 17/05/2020

DOl: $10.17230 /$ nfp16.94.2

\section{Resumen}

La apertura de las fronteras y la globalización de muchas actividades comerciales han fomentado el desarrollo de la delincuencia transfronteriza. En Suiza, como en Europa o en América Latina, se han acrecentado los procedimientos penales de dimensión internacional contra las empresas. El artículo 102 del Código Penal suizo se presenta como un instrumento fundamental en la lucha contra la criminalidad empresarial. Sin embargo, desde el reconocimiento de la punibilidad de las empresas en el derecho penal suizo, en 2003, una cuestión esencial seguía sin resolver: iprevé la ley un nuevo delito empresarial o una forma sui generis de participación a un delito cometido por una persona física? En su sentencia del 12 de diciembre de 2019, el Tribunal Federal suizo aclaró este aspecto fundamental, que influye tanto en la aplicación espacial de la responsabilidad penal de las empresas como en cuanto a la competencia de las

* Doctor en derecho, Certificate in Advanced Studies en la magistratura penal. Docente adjunto a la Cátedra de Derecho Penal y Criminología de la Universidad de Friburgo (Suiza). Contacto: thierry. godel@unifr.ch. 
46 La aplicación espacial de la responsabilidad penal de la empresa en el derecho penal suizo a la luz de la reciente jurisprudencia del Tribunal Federal - THIERRY GodeL

autoridades suizas.

\section{Abstract}

The opening of borders and the globalisation of many commercial activities have encouraged the development of cross-border crime. In Switzerland, as in Europe or Latin America, there has been a resurgence of criminal proceedings with an international dimension against companies. Article 102 of the Swiss Penal Code appears as a fundamental instrument in the fight against corporate crime. However, since the recognition of a corporate criminal responsibility in the Swiss Criminal Law, in 2003, a key issue remained unresolved: does the law provide a new corporate crime or a sui generis form of participation in a crime committed by a natural person? In its judgement of 12th December 2019, the Swiss Federal Court clarified this fundamental aspect which influences the spatial application of the corporate criminal responsibility, respectively the competence of the Swiss authorities.

\section{Palabras Clave}

Responsabilidad de la empresa, delito empresarial en el espacio, derecho penal en el espacio, derecho penal suizo.

\section{Keywords}

Corporate criminal responsibility, Corporate crime in space, Criminal Law in space, Swiss Criminal Law.

\section{Sumario}

1. Introducción. 2. La sentencia del Tribunal Federal suizo del 19 de diciembre de 2019. 3. El sistema de responsabilidad penal de la empresa del Código Penal suizo. 3.1. Societas delinquere non potest. 3.2. El sistema mixto de responsabilidad penal de las empresas. 3.2.1. La responsabilidad subsidiaria. 3.2.2. La responsabilidad principal. 3.3. El concepto ampliado de empresa. 4. La ubicación del delito imputable a la empresa. 4.1. Los criterios de vinculación al Código Penal suizo. 4.2 La competencia territorial. 4.3. Las competencias extraterritoriales. 5. Conclusión. 6. Bibliografia.

\section{Introducción}

En nuestras sociedades modernas, las empresas (en el sentido más amplio del término) ocupan un lugar privilegiado, participando activamente en el desarrollo de 
las economías nacionales y en la evolución de las tecnologías, y como componentes esenciales del proceso social'1 . Aunque sus actividades están motivadas esencialmente por intereses de lucro y de rentabilidad, no debe subestimarse su papel político. Por ejemplo, la adquisición de nuevos mercados o el establecimiento de la sede de una multinacional, su filial o su sucursal se negocia a menudo a nivel político.

La apertura de las fronteras y la globalización de muchas actividades comerciales han fomentado el desarrollo de la delincuencia transfronteriza. Desde hace varios años, se han intensificado los procedimientos penales de dimensión internacional contra las personas naturales, pero también contra empresas nacionales lo nacionalizadas) o multinacionales, en virtud del artículo 102 del Código Penal suizo².

El Informe Anual 2019 del Ministerio Público de la Confederación, publicado en abril de 2020, confirmó esta tendencia y demostró que los mayores casos complejos (que requieren numerosos procedimientos penales) se refieren a la corrupción y al blanqueo de dinero, en los que están implicadas empresas suizas o extranjeras con una fuerte repercusión en la política nacional ${ }^{3}$.

A fines ilustrativas, nos refirimos a los casos judiciales "grupo Gunvor" y "Petrobas y Oderbrecht", de nivel internacional, los cuales tratan de soborno de funcionarios públicos extranjeros y blanqueo de dinero. El grupo Gunvor (activo en el comercio de energía, con sede registrada en Ámsterdam y con centros operativos principales en Ginebra y Singapur) fue condenado por ordenanza penal del 14.10.2019 por graves deficiencias en su organización interna ${ }^{4}$. Las investigaciones establecieron que el negociante de petróleo no había tomado medidas para prevenir, entre 2008 y 2011, la corrupción de funcionarios públicos de la República del Congo y de Costa de Marfil en el curso de sus actividades comerciales. Esta corrupción, que tenía por objeto acceder a los mercados petroleros de dichos países, fue objeto de una primera sentencia condenatoria del Tribunal Penal Federal en $2018^{5}$.

$1 \quad$ Sentencia del 20.03.1996 del Tribunal federal (ATF) N²122, Vol. IV, pp. 103 y s. (las sentencias publicadas por el Tribunal Federal suizo pueden consultarse: www.bger.ch). Hurtado Pozo, José, Godel, Thierry, Droit pénal général, 3ª ed., Ginebra, Schulthess, 2019, p. $401, N^{\circ} 996$.

2 Del 21 de diciembre de 1937. RS 311.

3 Ministerio Público de la Confederación, Informe de gestión 2019, Berna (https://www. bundesanwaltschaft.ch).

4 Sobre este caso: Ibíd., p. 13 ; Comunicado de prensa del Ministerio Público de la Confederación del 17.10.2019 (https://www.bundesanwaltschaft.ch).

5 Sentencia del 28.08.2018 del Tribunal penal federal ( $N^{\circ}$ SK.2018.38) (https:// wwwbstger.ch). El Grupo Gunvor no tenía un código de conducta para dar una señal 
En el contexto del caso de corrupción internacional que implica la empresa semi-estatal brasileña Petrobras y el conglomerado Odebrecht, se han abierto más de 50 procedimientos penales en Suiza (a nivel federal) o en el extranjero (en Brasil o en los EE.UU.) desde abril de 2014, en particular por sospechas de blanqueo de dinero (artículo $305^{\text {bis }}$ del Código Penal suizo) y de soborno de funcionarios públicos extranjeros (artículo 322 $2^{\text {septies}), ~ d o s ~ d e ~ l o s ~ c u a l e s ~ s e ~ d i r i g e n ~ c o n t r a ~ i n s t i t u c i o n e s ~}$ financieras con sede en Suiza, sospechosas de un defecto de organización interna que permitió cometer delitos. Por ordenanza penal del 21.12.2016, las empresas brasileñas Odebrecht SA y Constructora Norberto Oderbrecht SA (CNO) ya han sido condenas por no haber adoptado todas las medidas organizativas razonables y necesarias para prevenir estos tipos de infracciones ${ }^{6}$.

En Suiza, al igual que en toda Europa o en países de América Latina, se ponen a disposición de las autoridades penales cada vez más recursos técnicos y humanos para reprimir los delitos empresariales. El importe de las multas impuestas, así como las reclamaciones de indemnización, probablemente tienen algo que ver con este repentino interés de las autoridades federales.

Por ejemplo, el grupo Gunvor tuvo que pagar una suma de casi 94 millones de francos suizos (correspondiente a los beneficios totales obtenidos por el grupo en los casos en cuestión en la República del Congo y en Costa de Marfil), incluida una multa de 4 millones?. En otro caso, las empresas brasileñas Odebrecht SA y CNO fueron condenadas el 21.12.2016 a pagar una multa conjunta y solidaria de 117 millones de francos suizos. En 2019, las autoridades suizas devolvieron al menos 365 millones a los perjudicados en Brasil, y confiscaron activos por un total de 700 millones.

El enjuiciamiento de las multinacionales o de empresas extrajeras en Suiza plantea la delicada cuestión de la aplicación espacial de la responsabilidad de las empresas. La ley suiza no dice nada al respecto y las teorías contradictorias

clara y guiar a los empleados en sus actividades, ni un programa de compliance. La empresa tampoco intentó gestionar el riesgo de corrupción relacionado con el uso de agentes para obtener cargamentos de petróleo y a los que se pagaron comisiones de varias decenas de millones de dólares americanos, entre 2009 y 2012. En particular, Gunvor no seleccionó los agentes utilizados y no supervisó su actividad.

6 Sobre este caso: Ministerio publico de la Confederación, Informe de gestión 2019, cit., p. 13 ; Informe de gestión 2018, Berna, p. 19; Informe de gestión 2017, Berna, p. 20 ss. ; Informe de gestión 2016, Berna, p. 19 ; Comunicados de prensa del Ministerio Público de la Confederación del 09.04.2019 y del 22.10.2019 (https://www. bundesanwaltschaft.ch).

7 Según el artículo 71, párrafo 1 del Código Penal suizo, se presenta una demanda de indemnización si los bienes que se van a confiscar ya no están disponibles directamente. 
sobre las diversas cuestiones de fondo relativas a la responsabilidad penal de las empresas, en particular sobre la índole del artículo 102 del Código Penal suizo, han alimentado el debate doctrinal durante muchos años sin aportar soluciones consensuadas. Además, el Tribunal Federal nunca ha tenido ocasión de pronunciarse sobre la aplicación espacial de esta norma, en particular por dos razones procesales: primero, muchas empresas son condenadas por ordenanza penal (artículos 352 y ss del Código de Procedimiento Penal suizo ${ }^{8}$ ) ; segundo, el procedimiento simplificado (artículos 358 y ss del Código de Procedimiento Penal suizo) permite a las empresas y al fiscal «negociar» el reconocimiento del delito contra una multa moderada, para evitar un juicio formal y la publicidad negativa resultante, a condición de que se acepten las demandas civiles y que el acuerdo (concretamente la acusación formulada) sea respaldado por un tribunal.

Recientemente, el Tribunal Federal resolvió de forma indirecta la cuestión de la aplicación espacial de la responsabilidad de la empresa, pronunciándose (ipor fin!) sobre la naturaleza del artículo 102 del Código Penal suizo en un caso relativo a la prescripción del delito imputado a la empresa.

Este artículo trata de los elementos de derecho penal sustantivo en los que se funda la responsabilidad penal de la empresa en el espacio - respectivamente la represión de las empresas suizas por delitos transnacionales, o de las multinacionales por actos ilícitos cometidos en territorio suizo. Ilustraremos nuestras palabras refiriéndonos a uno u otro caso relatado por los medios de comunicación. Sin embargo, nos abstendremos de referirnos a los aspectos procesales de la persecución penal de la empresa (foro, designación del representante de la empresa, confiscación de activos, asistencia jurídica mutua, etc.).

\section{La sentencia del Tribunal Federal suizo del 19 de diciembre de 2019}

En su sentencia del 12.12.20199 ${ }^{9}$, el Tribunal Federal aclaró ciertos aspectos fundamentales de la responsabilidad penal de las empresas. Desde 2003, seguía abierta la cuestión de si el artículo 102 del Código Penal suizo constituía una norma de imputación, creando una forma sui generis de participación a un delito cometido por una persona física, del que era responsable la empresa ${ }^{10}$, o si la norma materializaba

8 RS 312.

$9 \quad$ Sentencia del Tribunal Federal (6B _ 31/2019) del 19.12.2019, no publicada.

10 Esta teoría fue defendida desde el principio por la doctrina mayoritaria: HuRTAdo Pozo, 
un nuevo "delito de defecto de organización», constituyendo el delito imputado a la empresa sólo una condición objetiva de punibilidad ${ }^{11}$.

El Tribunal Federal, que debía pronunciarse sobre un recurso del Ministerio público del Cantón de Argovia, relativo a la prescripción de la responsabilidad penal de una empresa ${ }^{12}$, confirmó que el artículo 102 es una norma de imputación, y que el defecto de organización empresarial no era un delito autónomo. Los jueces federales subrayaron, por un lado, que este enfoque se ajustaba al carácter sistemático de la ley (la norma figura en la parte general del Código Penal suizo) y a la voluntad del legislador y, por otro, que el fallo de organización era sólo un elemento que permitía imputar el delito "de la persona natural" a la empresa. Sobre este último punto, el Tribunal Federal recordó que la cuantía de la multa no sólo dependía de la gravedad de la deficiencia de organización, sino que debían tenerse además en cuenta otros criterios (por ejemplo,

José, "La responsabilidad penal de la empresa en el derecho penal suizo", en Derecho Penal y Criminología, Vol. 29, N86-87, Bogotá, Universidad Externado de Colombia, (1) 2008, pp. 95-116 (en particular, p. 104 y ss) ; Hurtado Pozo, José, Godel, Thierry, Droit pénal général, cit., No 1005 ss., pp. 404 ss.; Macaluso, Alain, Garbarski, Andrew M., "L'article 102 CP ne consacre pas une infraction de mauvaise organisation", en Pratique Juridique Actuelle, Zurich, Dike, (2) 2019, pp. 194-200 ; CASSANI, Unsula, "Responsabilité(s) pénale(s) de l'entreprise", en Chappuis Christine, Winiger Bénédict (coord.), Responsabilité civile - Responsabilité pénale, Schulthess, Genève, 2015, pp. 103 ss.

11 A favor de esta teoría: Nigglı, Marcel A., Gfeller, Diego R., en Niggli, Marcel A, Wiprächtiger, Hans (coord.), Basler Kommentar, Strafrecht I-II, $4^{\mathrm{a}}$ ed., Basilea, Helbing Lichtenhahn, 2019, art. 102, № 19 ss. Según ellos, el artículo 102 del Código Penal suizo constituye un delito sui generis que incrimina (1) la omisión de adoptar medidas organizativas razonables y necesarias o (2) el establecimiento activo de una estructura que impide la identificación de las personas físicas responsables o que oculta el delito cometido. El comportamiento delictivo sería la transgresión de normas administrativas o civiles (normas de cumplimiento) de las que la empresa es responsable penalmente desde el momento en que esta violación está vinculada causalmente a una infracción cometida en el contexto de las actividades empresariales. El Tribunal Federal rechazó con razón esta teoría de que la competencia de las autoridades suizas sólo existiría si el delito de desorganización fuese ubicado en Suiza (es decir, si la empresa tuviese su sede o su estructura decisoria en Suiza). Entonces, la responsabilidad penal de la empresa estaría vinculada al lugar del defecto de organización y no al lugar del delito cometido por la persona física.

12 Las consecuencias prácticas de estas dos teorías son considerables, en particular en lo que respecta a la prescripción del delito: habida cuenta que el artículo 102 es una norma de imputación, el plazo de prescripción es el del delito subyacente (en general de 7, 10 o 15 años según el artículo 97); admitiendo que la norma crea un nuevo delito de defecto de organización, punible con una multa, el plazo de la prescripción correspondería al aplicable a las multas (limitado a 3 años según el artículo 109). 
la gravedad del delito o del daño) según el párrafo 3 del artículo $102^{13}$.

Aunque la sentencia no se refiere expresamente a ella, nos parece pertinente señalar que, según la doctrina que ya defendía la posición adoptada por la Corte Suprema, este defecto de organización constituye una forma sui generis de culpabilidad, ya que la persona jurídica está desprovista de conciencia: se admite la referencia a la «condición subjetiva del defecto de organización» atribuible a la empresa. La responsabilidad de demostrar la ausencia de desorganización culpable recae en la empresa ${ }^{14}$. Sin embargo, sólo se puede culpar a la empresa de la ausencia de medidas razonables y necesarias ${ }^{15}$.

\section{El sistema de responsabilidad penal de la empresa del Código Penal suizo}

\subsection{Societas delinquere non potest}

Tradicionalmente se ha considerado - no solo en Suiza - que las personas jurídicas no podían cometer delitos, porque no disponían de los elementos jurídicos suficientes para imputarle una responsabilidad penal. Concretamente, el legislador sostuvo que sólo la persona humana, como ser natural, poseía las capacidades físicas y psíquicas para actuar de manera culpable ${ }^{16}$.

Sin embargo, esta perspectiva ha cambiado de forma significativa con la reforma del Código Penal suizo en 2003 ${ }^{17}$. Con entrada en vigor del antiguo artículo

13 Según el párrafo 3 del artículo 102, la cuantía de la multa que se imponga a una empresa considerada responsable penalmente se determinará, en particular, en función de la gravedad del delito, la falta de organización, los daños causados y la capacidad económica de la empresa. La multa máxima es de 5 millones de francos suizos (párrafo 1). El derecho penal auxiliar puede prever multas por encima de este límite, teniendo en cuenta la capacidad financiera de la empresa (por ejemplo, el artículo 14 de la Ley sobre los cárteles [RS 251]).

14 DE Preux, PASCAL, "Entreprise et corruption: risques et responsabilité pénale", en Pratique Judiciaire Actuelle, (9) 2010, p. 1097.

15 Augsburger-Buchel, Isabelle, Perrin, Bertrand, "Les mesures d'organisation raisonnables et nécessaires, au sens de l'article 100quater alinéa 2 du Code pénal suisse, que doivent prendre les entreprises exportatrices pour empêcher la corruption d'agents publics étrangers", Zen-Ruffinen Piermarco, Mélanges en I'honneur de Pierre-Henri Bolle, Basilea, Helbing Lichtenhahn, 2006, pp. 59 ss.

16 Hurtado Pozo, José, Godel, Thierry, Droit pénal général, cit., № 998, p. 401.

17 Sobre el proceso legislativo: HuRtado Pozo, José, La responsabilidad penal de la empresa en el derecho penal suizo, cit., pp. 96 ss.; Hurtado Pozo, José, Responsabilité pénale de I'entreprise: culpabilité et peine, en Niggli Marcel A., Hurtado Pozo José, Queloz Nicolas 
100quater, se contempló la posibilidad de que los delitos cometidos por una empresa en el ejercicio de sus actividades comerciales pudieran suponer imputación penal de la compañía, al margen de las personas físicas concretas que la integraban. Con la reforma de la parte general del Código Penal suizo, culminada en enero de 2007, la norma ha sido reemplazada por el artículo 102, en el que se prevé un nuevo sistema de responsabilidad penal de la empresa. HuRTAdo Pozo nos recuerda que esta novedad fue "el resultado de un largo y agitado debate, cuyo resultado, sin embargo, está lejos de haber colmado las expectativas de quienes preconizaban una real y efectiva imputación de responsabilidad penal a las entidades colectivas ${ }^{18 "}$.

\subsection{El sistema mixto de responsabilidad penal de las empresas}

\section{Artículo 102 - punibilidad (de la empresa)}

1. Un crimen o delito que se cometa dentro de una empresa en el curso de actividades comerciales que estén de acuerdo con sus propósitos se atribuye a la empresa si no puede atribuirse a ninguna persona física específica debido a la falta de organización de la empresa. En este caso, la empresa será castigada con una multa de hasta cinco millones de francos.

2. En el caso de un delito previsto en los artículos 260ter, 260quinquies, 305bis, 322ter, 322quinquies, 322septies, párrafo 1, o 322octies, la empresa será castigada independientemente de la punibilidad de las personas físicas si se la acusa de no haber tomado todas las medidas organizativas razonables y necesarias para evitar dicho delito.

3. El tribunal fijará la multa, en particular, en función de la gravedad del delito, de la falta de organización y de los daños causados, y en función de la capacidad económica de la empresa.

4. Son empresas en el sentido del presente título:

a. las personas jurídicas de derecho privado;

(coord.): Festschrift für Franz Riklin zum 67. Geburtstag, Zurich, Schulthess, 2007, pp. 121-135 (p. 122 ss.) y referencias citadas; Consell fÉdÉRAL, Message concernant la modification du code pénal suisse (dispositions générales, entrée en vigueur et application du code pénal) et du code pénal militaire, ainsi qu'une loi fédérale régissant la condition pénale des mineurs du 21.09.1998 (R0 2003 3043, FF 2002 5014).

18 Hurtado Pozo, José, La responsabilidad penal de la empresa, cit., p. 96. 
b. las personas jurídicas de derecho público, con excepción de las corporaciones territoriales;

c. las sociedades;

d. las empresas en razón individual.

El artículo 102 del Código Penal suizo ${ }^{19}$ introduce un modelo de responsabilidad híbrido o mixto, mezclando:

- una responsabilidad subsidiaria de la empresa, destinada a compensar la imposibilidad de atribuir el delito a una persona física concreta (párrafo 1);

- una responsabilidad primaria, solidaria y autónoma para ciertos delitos exhaustivamente enumerados, en cuya prevención la persona jurídica está obligada a adoptar medidas de organización (párrafo 2).

La imputación de la infracción a cargo de la empresa se funda en cuatro elementos que también influyen en la aplicación de la norma en el espacio:

- un delito básico 0 subyacente ${ }^{20}$ resultante de un comportamiento humano cometido dentro de la empresa por una persona física en una relación jerárquica u organizativa con la empresa ${ }^{21}$; En relación con esta última condición, debe quedar claro que la autoridad penal tiene la obligación de establecer que se ha cometido un delito subyacente. En efecto, por sentencia de 11.10.201622, el Tribunal Federal aclaró que la empresa sólo podía ser considerada responsable

19 Por un comentario detallado del artículo 102: Dupuis, Michel, Moreillon, Laurent, Piguet, Christophe, Berger, Séverine, Mazou, Miriam, Rodigari, Virginie (coord.), Code pénal, Petit Commentaire, $2^{a}$ ed., Basilea, Helbing Lichtehahn, 2017, ad art. 102, № 1 ss.; Macaluso, AlalN, en Roth Robert, Moreillon Laurent (coord.), Commentaire romand, Code pénal I (art. 1-110), Balisea, Helbing Lichtehahn, 2009, ad. art. 102, Nº 1 ss.

20 El acto debe ser conforme a una declaración legal de hechos que constituyan un delito o un crimen - excluyendo las contravenciones según el art. 105 CPs. El comportamiento humano ilícito puede ser intentado o consumado.

21 En principio, se establece por la existencia de un contrato de trabajo, sobre la condición de órgano o miembro de un órgano. Sentencia del Tribunal Federal (N $6 B$ del 26.08.2013.

22 Sentencia del 11.10.2016 del Tribunal Federal (ATF 142 IV 333). Para un comentario de la sentencia: Strasse, Othmar, Villard, Katia, “Obergericht des Kantons Solothurn, Strafkammer, Urteil vom 19. November 2015 i.S. Staatsanwaltschaft des Kantons Solothurn gegen Die Schweizerische Post", en forumpoenale, Berna, Stämpfli Editions, (4) 2016, pp. 196-207; Macaluso, Alain, Garbarski, Andrew M., "La responsabilité pénale de l'entreprise après l'arrêt La Poste Suisse: réflexions sur les relations entre I'infraction sous-jacente et l'art. 102 CP", en Pratique Juridique Actuelle, Zurich, Dike, (1) 2017, p. 99-107. 
penalmente si se establecían todos los elementos objetivos y subjetivos de la infracción subyacente. En febrero de 2005, dos empleados del Servicio de correos suizo (Poste Suisse) habían preparado y entregado a un tercero 4,6 millones de francos suizos provenientes del extranjero. El procedimiento iniciado en 2007 contra un empleado del Servicio de correos suizo fue declarado concluido, en 2008, debido a la falta de elementos subjetivos del delito de blanqueo de dinero. La empresa, que había sido condenada por este delito en 2011 (artículos 305bis y 102, párr. 2 del Código Penal suizo), fue absuelta en apelación en 2015. El Tribunal Federal confirmó la sentencia un año después.

- la existencia de deficiencias organizativas relacionadas con la capacidad de identificar al autor a pesar de los intensos esfuerzos del Ministerio Público (párrafo 1) o con la facultad de impedir la comisión de uno de los delitos enumerados de manera exhaustiva en el párrafo $2^{23}$.

- la existencia de una conexión entre el delito básico y las actividades comerciales de acuerdo con el propósito, aunque el delito individual esté incluido en el catálogo de disposiciones a que se refiere el párrafo 2;

- una relación causal entre las deficiencias organizativas observadas y la imposibilidad de identificar al autor o de constatar todos los elementos objetivos y subjetivos del delito (párrafo 1) o la prevención del delito cometido (párrafo 2).

Los dos tipos de responsabilidad de la empresa implican que sus representantes no puedan ser considerados responsables (artículo 29 del Código Penal suizo) ${ }^{24}$.

23 Hurtado Pozo, José, Responsabilité pénale de l'entreprise, cit., p. 130 observa que las causas del defecto organizativo es esencialmente el resultado de una política o una administración deficiente de la empresa.

24 La responsabilidad del empresario (artículos 29 del Código Penal suizo o 6 de la Ley sobre el Derecho Penal Administrativo [RS 313]) presupone una posición de garante, es decir, la existencia de una obligación legal específica de impedir la conducta en cuestión ejerciendo la supervisión, dando instrucciones e interviniendo en caso necesario. Dado que, por regla general, las normas de derecho administrativo están dirigidas al empresario, debe suponerse que éste está legalmente obligado a garantizar su aplicación o a impedir su violación. En este caso se admite la responsabilidad penal, ya que el empresario no ha tomado las medidas adecuadas ni ha dado las instrucciones adecuadas a su personal. Macaluso, Alain, en Roth Robert, Moreillon Laurent (coord.), Commentaire romand, Code pénal I (art. 1-110), cit., ad. art. 102, N 65 ss.; Perrin, Bertrand, de Preux, Pascal, "Responsabilité pénale de l'entreprise et de son chef", en Perrin Bertrand, de Preux Pascal (coord.), L'investigation en entreprise Prévention et détection des fraudes, Lausana, Presse polytechniques et universitaires romandes, 2018, pp. 223-230; Garbarski, Andrew M., Macaluso, Alain, La responsabilité de l'entreprise et de ses organes dirigeants à l'épreuve du droit pénal administratif, 
Además, en lo que respecta a la responsabilidad penal de los medios de comunicación, debe tenerse en cuenta el artículo 28 del Código Penal suizo ${ }^{25}$.

\subsubsection{La responsabilidad subsidiaria}

Como hemos explicado antes, el artículo 102 del Código Penal suizo establece una doble responsabilidad empresarial. En principio, los actos delictivos cometidos por una persona física no son imputables a la empresa. Sin embargo, los actos delictivos son imputables a la entidad jurídica si el autor no puede ser identificado debido a una "falta de organización culpable de la empresa» (párrafo 1). La responsabilidad subsidiaria de la empresa se presenta entonces si no se han tomado las medidas organizativas razonables y necesarias. Por lo tanto, debe existir un vínculo causal entre el defecto de organización y la imposibilidad de atribuir el acto delictivo a un autor físico.

La responsabilidad subsidiaria de la empresa supone que el delito cometido dentro de la empresa es un delito o un crimen en el sentido del artículo 10 del Código Penal suizo, a la legislación penal federal complementaria (en referencia del artículo 333, párrafo 1 del Código Penal suizo) o a la legislación fiscal cantonal (en referencia del artículo 335, párrafo 2 del Código Penal suizo). La responsabilidad de la empresa queda expresamente excluida en caso de contravenciones (artículo 105, párrafo del Código Penal suizo).

Para ilustrar nuestras palabras, nos referimos primero a la primera condena en aplicación de la responsabilidad de la empresa. En 2005, una sociedad de transporte francesa fue multada con 3.000 francos suizos por una infracción calificada al Código sobre la circulación vial (párrafo 2 del artículo 9026 ${ }^{26}$, porque no pudo identificar al empleado que había cometido el delito27.

Otro caso, que fue relatado por los medios de comunicación, es el del "Dieselgate". Desde diciembre de 2016, el Ministerio Público de la Confederación investiga a Volkswagen AG (Alemania) y AMAG Import AG (Suiza) por sospecha de fraude (párrafo 1 del artículo 102 en relación con el artículo 146 del Código Penal suizo), y a los órganos responsables y los empleados de AMAG Import AG sospechosos de fraude profesional (artículo 146, párrafos 1 y 2). Las empresas y

Pratique Juridique Actuelle, (7) 2008, pp. 833 ss.

25 Hurtado Pozo, José, Godel, Thierry, Droit pénal général, cit., pp. 410 ss.

26 RS 741.01.

27 Revue fribourgeoise de jurisprudence (RFJ) 2005, p. 59. 
sus dirigentes están acusados haber perjudicado, entre 2008 y 2015 en Suiza, los bienes de aproximadamente 175,000 compradores y arrendatarios de vehículos de las marcas del Grupo VW con motores diesel de tipo EA 189 por una cantidad indeterminada. Ellos eran, al menos parcialmente, conscientes de las emisiones contaminantes ${ }^{28}$.

\subsubsection{La responsabilidad principal}

La responsabilidad primaria de la empresa se compromete independientemente de que se haya identificado o no al autor material (artículo 102, párrafo 2 del Código Penal suizo). La empresa sólo es responsable de los siguientes delitos graves enumerados: organización delictiva (artículo 260ter del Código Penal suizo), financiación del terrorismo (artículo 260quinquies), blanqueo de dinero (artículo 305bis), corrupción activa (artículo 322ter), concesión de una ventaja (artículo 322quinquies), corrupción de funcionarios públicos extranjeros (artículo 322septies, párrafo 1) y corrupción privada activa (art. 322octies).

Esta responsabilidad se basa en la posición de la empresa como garante de la misma, es decir como titular del deber de supervisión de sus órganos y miembros. La empresa es responsable por no haber tomado las medidas necesarias y razonables para prevenir ciertos delitos inherentes a las actividades de la empresa, y por haber aumentado los riesgos o favorecido su realización con una organización irregular ${ }^{29}$.

Para ilustrar nuestras palabras, nos referimos al caso relatado por los medios de comunicación en el que fueron implicadas sociedades suizas y franceses del grupo Alstom. Por ordenanza penal de 22.11.2011, el Fiscal federal condenó a Alstom Network Schweiz AG por soborno de funcionarios públicos extranjeros (artículo 102, párrafo 2 del Código Penal suizo en relación con el art. 322septies) a una multa de 2,5 millones de francos suizos y al pago de una indemnización de 36,4 millones. La empresa fue declarada culpable de no haber adoptado todas las medidas organizativas razonables e indispensables para impedir el pago de sobornos a funcionarios públicos extranjeros a fin de obtener contratos en el sector de la energía en Letonia, Túnez y Malasia en octubre de 2003. La investigación penal dirigida también contra Alstom SA, cuyo domicilio social se encuentra en Francia, fue

28 Ministerio publicó de la Confederación, Informe de gestión 2019, pp. 19 s.; Comunicado de prensa del Ministerio público de la Confederación del 02.09.2019.

29 Hurtado Pozo, José, Responsabilité pénale de l'entreprise, cit., p. 131. Hurtado Pozo, José, Godel, THIERRY, Droit pénal général, cit., p. 408. 
concluida, de conformidad con el artículo 53 del Código Penal suizo, respecto de los actos cometidos en Letonia, Túnez y Malasia, corriendo los gastos del procedimiento relativo a Alstom SA a cargo de la empresa ${ }^{30}$.

La doble sanción de la persona física responsable de la infracción y de la empresa incumplidora no es contraria al principio de ne bis in idem ${ }^{31}$.

Por ejemplo, en el marco de las investigaciones realizadas desde 2011 en relación con las actividades de Gunvor en la República del Congo y Costa de Marfil, varias personas físicas - empleados del comerciante de petróleo o de intermediarios financieros - siguen siendo investigadas, entre otras cosas, por sospechas de soborno de funcionarios públicos extranjeros (artículo 322septies del Código Penal suizo), blanqueo de dinero (artículo 305bis) y gestión desleal (artículo 158).

La responsabilidad directa tiene prioridad sobre la subsidiaria cuando ambas se cumplen. En otras palabras, si se ha cometido uno de los delitos enumerados en el párrafo 2 del artículo 102 del Código Penal suizo y no se puede identificar al autor físico, se debe mencionar la incapacidad de la organización para prevenir determinados delitos. Esta aclaración no carece de interés, ya que en un grupo de empresas, las dos formas de desorganización pueden ser responsabilidad de dos entidades diferentes en función de la división de tareas.

\subsection{El concepto ampliado de empresa}

El párrafo 4 del artículo 102 del Código Penal suizo indica la lista exhaustiva de las entidades jurídicas, de derecho privado o público, que entran en la definición de "empresa". La ley crea un concepto autónomo, específico del derecho penal suizo, de la empresa, comprensivo de toda persona jurídica y también de las sociedades sin personalidad jurídica, que, a falta de órganos en el sentido formal, poseen cuasiorganismos, es decir, personas físicas a través de las cuales «piensan y actúan».

Sólo las entidades jurídicas que tienen una estructura económica organizada (es decir una actividad comercial) pueden incurrir en responsabilidad penal (subsidiaria o primaria). Se excluye por ejemplo a las asociaciones o fundaciones sin fines de lucro de ser condenadas por soborno de funcionarios públicos, blanqueo de dinero o financiación del terrorismo. Las sociedades simples que no se dedican

30 Ministerio publicó de la Confederación, Informe de gestión 2011, pp. 23 y s.; Comunicado de prensa del Ministerio público de la Confederación del 22.11.2011.

31 Huntado Pozo, José, Responsabilité pénale de l'entreprise, cit., p. 131; Hurtado Pozo, José, Godel ThierRY, Droit pénal général, cit., p. 408. 
a ninguna actividad comercial (por ejemplo, porque sólo poseen bienes) no incurren en responsabilidad penal en el sentido del artículo 102 del Código Penal suizo. Sin embargo, si estas diversas entidades se consideran organizaciones criminales 0 terroristas en el sentido del artículo 260 ${ }^{\text {ter }}$ del Código Penal suizo (que se revisará próximamente), sus miembros pueden ser considerados participantes.

En contraste con el concepto de «persona jurídica» generalmente utilizado en el derecho internacional y en el derecho interno extranjero, el concepto de "empresa» en el derecho penal suizo abarca las empresas multinacionales y otros grupos de empresas (empresa matriz y una o más filiales) ${ }^{32}$.

\section{La ubicación del delito imputable a la empresa}

\subsection{Los criterios de vinculación al Código Penal suizo}

El legislador suizo somete ciertas conductas al derecho penal suizo determinando los criterios de conexión, por ejemplo, el lugar de la acción penal o del resultado jurídico, la naturaleza del delito, la nacionalidad del autor o de la parte lesionada, la existencia de una delegación de tratado debido a un interés internacionalmente protegido.

Los criterios de conexión territorial y extraterritorial establecidos en los artículos 3 a 7 del Código Penal suizo regulan el ámbito de aplicación de la ley en el espacio para los delitos cometidos por personas naturales. Respecto a la responsabilidad penal de la empresa, debe considerarse si los mismos criterios deben aplicarse.

En relación con la índole del artículo 102 del Código Penal suizo (una norma de imputación), dos criterios de conexión subyacen a la jurisdicción suiza sobre los delitos transnacionales ${ }^{33}$ :

- el lugar del delito básico (acción o resultado como elemento del delito).

- la localización del defecto de organización que dificulta la identificación del autor (responsabilidad subsidiaria) o no impide la comisión de un delito (responsabilidad primaria).

Se admite sin reservas la conexión territorial del artículo 102 del Código Penal suizo con el lugar donde el delito subyacente ha ocurrido, independientemente de

32 Villard Katia, Anne, La compétence du juge pénal suisse à l'égard de l'infraction reprochée à l'entreprise, Avec un regard particulier sur les groupes de sociétés, Zurich, Schulthess, 2017, se interesa especialmente en la responsabilidad de la empresa matriz y sus filiales.

33 Ibíd., pp. 284-305. 
que la sociedad tenga su sede en Suiza o en el extranjero. Lo mismo se aplica al lugar donde la empresa debería haber adoptado las medidas organizativas razonables y necesarias para garantizar la identificación del autor (párrafo 1) 0 impedir que se cometa el delito (párrafo 2).

En el caso de los grupos de empresas, puede ocurrir que la falta de organización no sea responsabilidad de la empresa en la que se cometió el delito subyacente. La imputación a una sociedad de un delito cometido en otra del mismo grupo implica que la sociedad matriz (o su filial) sea la garante de la sociedad en cuestión. Esto implica, en particular, establecer quién tiene competencia para tomar decisiones en relación con el defecto de organización que impide identificar al autor (párrafo 1) 0 la ausencia o falta de medidas para prevenir determinados delitos específicos (párrafo 2), y evaluar la autonomía de la empresa en cuestión. En la práctica, el juez se considera la importancia de la participación de una empresa en su filial 0 empresa hermana, la distribución del poder para dar instrucciones, la integración de las estructuras de gestión, la identidad de los directores, incluso las apariencias y la confianza creada entre los socios y el público.

\subsection{La competencia territorial}

\section{Articulo 3 - Crímenes o delitos cometidos en Suiza}

1 Este Código se aplica a todo aquel que cometa un delito o un crimen en Suiza. $2[\ldots]$

\section{Articulo 8 - Lugar de comisión del acto}

1 Se considerará que un delito 0 un crimen se ha cometido tanto en el lugar donde el autor actuó o debió actuar como en el lugar donde se produjo el resultado.

2 La tentativa se considerará cometida tanto en el lugar donde el autor la realizó como en el lugar donde, en su opinión, se produjo el resultado.

Según los artículos 3 (principio de territorialidad) y 8 (principio de ubicuidad relativa ${ }^{34}$ ) del Código penal suizo el delito principal se comete en Suiza:

34 En lo que respecta a la responsabilidad de las empresas por las actividades subcontratadas: Cassani Ursula, Villard, Katia, Anne, "La responsabilité pénale pour I'infraction commise dans le cadre d'activités outsourcées", en Jositsch, Daniel, Schwarzenegger, Christian, Wohlers, Wolfgang (coord.), Festschrift für Andreas 
- en el lugar de la acción (delito de comisión) o de la abstención (delito de omisión propiamente dicho o impropio), en caso de delitos continuos 0 repetidos, el accionar debe localizarse, al menos parcialmente, en el territorio suizo;

- en el lugar en que se produjo el resultado o en el que debería haberse producido (para los delitos materiales consumados 0 intentados, respectivamente).

En el caso de determinados delitos -en particular los de carácter formal pero también los materiales- el Tribunal Federal acepta excepcionalmente una interpretación amplia del «resultado», refiriéndose al «resultado buscado por el autor» (se trata de la noción subjetiva de resultado, que se refiere en particular a los delitos dolosos).

En cuanto al defecto de organización, si el delito básico se comete en el extranjero, debe estar ubicado en la sede suiza de la empresa o de la sociedad del grupo que tiene una posición de garante.

\subsection{Las competencias extraterritoriales}

Cuando no exista un factor de conexión territorial de Suiza, respectivamente cuando tanto el delito subyacente como el defecto de organización están localizados en el extranjero, la competencia de las autoridades suizas puede fundarse en otros principios $^{35}$ :

- la competencia real o de defensa del Estado por delitos contra el Estado (artículo 4 del Código Penal suizo) ${ }^{36}$;

- la competencia universal por los delitos sexuales graves cometidos en el extranjero contra menores (artículo 5) ${ }^{37}$;

- competencia delegada derivada de un acuerdo o convenio internacional

Donatsch, Zurich, Schulthess, 2017, pp. 583 ss.

35 En cuanto a la aplicación espacial del artículo 102 del Código Penal suizo en relación con los artículos 4 a 7: Dupuis, Michel, Moreillon, Laurent, Piguet, Christophe, Berger, Séverine, Mazou, Miriam, Rodigari, Virginie (coord.), Code pénal, Petit Commentaire, cit., ad art. $102, \mathrm{~N}^{\circ} 30$ y referencias citadas.

36 Por ejemplo, en caso de espionaje político, industrial o militar (art. 272 a 274 CPs) por parte de empleados de una empresa de seguridad o de limpieza.

37 Por ejemplo, en caso de actos sexuales con menores a cambio de remuneración o coacción sexual con menores de 14 años en el contexto de viajes de negocios u organizados por la filial extranjera de una agencia de viajes. 
firmado por Suiza con uno o más Estados (artículo 6) 38;

- la competencia extraterritorial ordinaria, respectivamente los principios de la personalidad activa ${ }^{39}$ y pasiva ${ }^{40}$ (artículo 7, párrafo 1);

- o la competencia extraterritorial extraordinaria (sustitutiva o universal) para los delitos castigados por la comunidad internacional (artículo 7, párrafo 2).

En lo que respecta a la competencia real del Estado, que es una expresión de la soberanía estatal para los delitos contra Suiza, se admite independientemente de que la empresa tenga o no su sede en el extranjero.

La responsabilidad de la empresa es también admitida cuando se cumplen los requisitos de los artículos 5 a 7 del Código Penal suizo, pero solo si la empresa tiene su sede social 0 una filial en Suiza ${ }^{41}$. En efecto, en el caso del autor material, la competencia del juez suizo sólo se admite si la persona se encuentra en el territorio suizo (la ley se refiere al «lugar de detención» y a la «ausencia de extradición»). Nos parece oportuno precisar que la obligación procesal de la empresa de nombrar un representante no permite considerar que esté ubicada en Suiza.

Los autores discrepan sobre si la persona jurídica debe ser también punible conforme al derecho extranjero, es decir, si debe reconocerse la obligación de la doble incriminación y la aplicación de la lex mitior establecida en los artículos 6 y 7 del Código Penal suizo. Esta cuestión es oportuna, ya que los instrumentos europeos, por ejemplo, solo imponen a los Estados que adopten sanciones "eficaces, proporcionadas y disuasorias», dejándoles la opción de elegir entre la responsabilidad penal 0 una forma alternativa de responsabilidad administrativa 0

38 Algunas convenciones prevén la obligación de demandar a las personas jurídicas, pero sin referirse a la empresa. Por ejemplo, en relación con el soborno de funcionarios públicos extranjeros, la financiación del terrorismo o la delincuencia transnacional. La obligación de enjuiciar, que constituye la base de la competencia material de las autoridades suizas, debe distinguirse de las obligaciones procesales a las que pueden estar sujetas (por ejemplo, la obligación de confiscar el producto del delito de conformidad con el Convenio Europeo sobre el Blanqueo de Dinero de 1990).

39 El autor es de nacionalidad suiza o la empresa tiene su sede principal en Suiza. Estos principios ya estaban consagrados en la jurisprudencia federal (ATF 121 IV 145).

40 La víctima es de nacionalidad suiza o la empresa perjudicada tiene su sede en Suiza.

41 Algunas Convenciones internacionales prevén la obligación de demandar a las personas jurídicas, pero sin referirse a la empresa. Por ejemplo, en relación con el soborno de funcionarios públicos extranjeros, la financiación del terrorismo o la delincuencia transnacional. La obligación de enjuiciar, que constituye la base de la competencia material de las autoridades suizas, debe distinguirse de las obligaciones procesales a las que pueden estar sujetas (por ejemplo, la obligación de confiscar el producto del delito de conformidad con el Convenio Europeo sobre el Blanqueo de Dinero de 1990). 
civil. Falta consenso sobre la responsabilidad empresarial en los países europeos ${ }^{42}$ :

- el legislador italiano, muy apegado al adagio "societas delinquere non potest», estatuyó una forma de responsabilidad administrativa por los delitos penales mediante la ley 231/2001 del 8 de junio de 2001;

- la legislación alemana sólo reconoce la responsabilidad administrativa sin carácter penal (la persona jurídica no puede ser culpable de un delito);

- la legislación francesa establece la responsabilidad penal de las personas jurídicas (mediante un mecanismo sui generis de atribución de la culpa a un órgano o representante de la persona jurídica), pero ésta se limita a las agrupaciones con personalidad jurídica (con exclusión de las empresas multinacionales, los grupos de empresas, las sociedades de hecho, etc.).

Una parte de la doctrina suiza, a la que nos adherimos, admite que sólo se debe considerar el derecho suizo en presencia de una violación de una obligación de diligencia (due diligence) por una multinacional. Así, se podría admitir la competencia extraterritorial de Suiza por hechos de los que sería responsable la sociedad matriz o una sucursal situada en el extranjero, siempre que el grupo empresarial tenga un establecimiento permanente en Suiza.

\section{Conclusión}

El reconocimiento del artículo 102 del Código Penal suizo como norma de imputación por el Tribunal Federal tiene importantes consecuencias para la aplicación espacial de la responsabilidad de las empresas. Si bien quedan algunas cuestiones pendientes, en particular en lo que respecta a su aplicación a las infracciones cometidas en el extranjero, cuando el defecto de organización se da en el extranjero, las competencias de las autoridades penales suizas son amplias. En este sentido, el artículo 102 del Código Penal suizo es un instrumento fundamental en la lucha contra la delincuencia empresarial transnacional y la impunidad de las multinacionales. Sin embargo, la materialización en la Ley nacional de la responsabilidad penal de la empresa es sólo un instrumento entre otros. En la práctica, la asistencia judicial recíproca es la que influye realmente en el resultado de las investigaciones y procesos.

42 Atat, Korin, La responsabilité pénale des personnes morales, Droit de I'Union européenne et modèles européens, Balisea, Helbing Lichtehahn, 2018. 


\section{Bibliografía}

Atat, Korin, La responsabilité pénale des personnes morales, Droit de l'Union européenne et modèles européens, Balisea, Helbing Lichtehahn, 2018.

Augsburger-Buchelı, Isabelle, Perrin, Bertrand, "Les mesures d'organisation raisonnables et nécessaires, au sens de l'article 100quater alinéa 2 du Code pénal suisse, que doivent prendre les entreprises exportatrices pour empêcher la corruption d'agents publics étrangers", Zen-Ruffinen Piermarco, Mélanges en l'honneur de Pierre-Henri Bolle, Basilea, Helbing Lichtenhahn, 2006, pp. 57-70.

Cassani Ursula, "Responsabilité(s) pénale(s) de l'entreprise", en Chappuis, Christine, WinIGER, BÉnÉDICT (coord.), Responsabilité civile - Responsabilité pénale, Schulthess, Genève, 2015 pp. 103-135.

Cassani, Ursula, Villard, Katia Anne, "La responsabilité pénale pour l'infraction commise dans le cadre d'activités outsourcées", en Jositsch, Daniel, Schwarzenegger, Christian, Wohlers, Wolfgang (coord.), Festschrift für Andreas Donatsch, Zurich, Schulthess, 2017, pp. 583-603.

Consel fé́ÉRAL, Message concernant la modification du code pénal suisse (dispositions générales, entrée en vigueur et application du code pénal) et du code pénal militaire, ainsi qu'une loi fédérale régissant la condition pénale des mineurs du 21.09.1998, en Feuille Fédérale (FF) 2002, pp. 5014 ss.

de Preux, Pascal, Entreprise et corruption : risques et responsabilité pénale, en Pratique Judiciaire Actuelle, (9) 2010, pp. 1092-1098.

Dupuis, Michel, Morelllon, Laurent, Piguet, Christophe, Berger, Séverine, Mazou, Miriam, Rodigari, VIRginie (coord.), Code pénal, Petit Commentaire, $2^{a}$ ed., Basilea, Helbing Lichtehahn, 2017.

Garbarski, Andrew M., Macaluso, Alain, La responsabilité de l'entreprise et de ses organes dirigeants à l'épreuve du droit pénal administratif, Pratique Juridique Actuelle, (7) 2008, pp. 833-846.

Hurtado Pozo, José, "La responsabilidad penal de la empresa en el derecho penal suizo", en Derecho Penal y Criminología, Vol. 29, N86-87, Bogotá, Universidad Externado de Colombia, (1) 2008, pp. 95-116.

Hurtado Pozo, José, Responsabilité pénale de l'entreprise: culpabilité et peine, en Niggli, Marcel A., Hurtado Pozo, José, Queloz, Nicolas (coord.): Festschrift für Franz Riklin zum 67. Geburtstag, Zurich, Schulthess, 2007, pp. 121-135.

Hurtado Pozo, José, Godel, Thierry, Droit pénal général, 3a ed., Ginebra, Schulthess, 2019. 
64 La aplicación espacial de la responsabilidad penal de la empresa en el derecho penal suizo a la luz de la reciente jurisprudencia del Tribunal Federal - THIERRY GodeL

Macaluso, Alain, artículo 102, en Roth, Robert, Morellonon, Laurent (coord.), Commentaire romand, Code pénal I (art. 1-110), Balisea, Helbing Lichtehahn, 2009

Macaluso, Alain, Garbarski, Andrew M., "L'article 102 CP ne consacre pas une infraction de mauvaise organisation", en Pratique Juridique Actuelle, Zurich, Dike, (2) 2019, pp. 194-200.

Macaluso, Alain, Garbarski, Andrew M., "La responsabilité pénale de l'entreprise après l'arrêt La Poste Suisse: réflexions sur les relations entre l'infraction sousjacente et l'art. 102 CP", en Pratique Juridique Actuelle, Zurich, Dike, (1) 2017, p. 99-107.

Ministerio Público de la Confederación, Informe de gestión 2019, Berna, 2019.

Ministerio Público de la Confederación, Informe de gestión 2018, Berna, 2018.

Ministerio Público de la Confederación, Informe de gestión 2017, Berna, 2017.

Ministerio Público de la Confederación, Informe de gestión 2016, Berna, 2016.

Ministerio Público de la Confederación, Informe de gestión 2011, Berna, 2011.

Niggli, Marcel A., Gfeller, Diego R., art. 102, en Niggl, Marcel A, Wiprächtiger, Hans (coord.), Basler Kommentar, Strafrecht I-II, $4^{a}$ ed., Basilea, Helbing Lichtenhahn, 2019.

Perrin, Bertrand, de Preux, Pascal, "Responsabilité pénale de l'entreprise et de son chef", en Perrin, Bertrand, de Preux, Pascal (coord.), L'investigation en entreprise - Prévention et détection des fraudes, Lausana, Presse polytechniques et universitaires romandes, 2018, pp. 223-230.

Strasse, Othmar, Villard, Katia Anne, Commentaire "Obergericht des Kantons Solothurn, Strafkammer, Urteil vom 19. November 2015 i.S. Staatsanwaltschaft des Kantons Solothurn gegen Die Schweizerische Post", en forumpoenale, Berna, Stämpfli Editions, (4) 2016, pp. 196-207.

Villard, Katia Anne, La compétence du juge pénal suisse à l'égard de l'infraction reprochée à l'entreprise, Genève, Collection genevoise, 2017. 